\title{
OS MEDIA E O ENSINO DA LÍNGUA MATERNA: ALGUMAS CONVICÇÕES FORTES
}

\author{
Isabel Margarida Duarte \\ Universidade do Porto
}

A reflexão que me proponho fazer enraíza-se na minha dupla experiência quer como docente de Metodologia do Ensino do Português, na Faculdade de Letras da Universidade do Porto, quer como colaboradora no Boletim mensal do projecto Público na Escola.

Como formadora de futuros professores de Português, sublinho algumas convicções acerca da utilidade de trabalhar com os media na aula de Língua Materna que deve ser, a meu ver, uma aula onde circule, como F. I. Fonseca e J. Fonseca (1977) ${ }^{1}$ defenderam, quase há três décadas, uma pluralidade de discursos. Por isso mesmo, nas minhas próprias aulas práticas são trabalhados textos dos media e em todas elas leio, aos estudantes universitários de cuja formação me encarrego, um artigo, uma notícia, uma entrevista ou outro texto de imprensa que considero ter interesse, porque fala de ensino em geral, de ensino da Língua Portuguesa, de algum escritor, de um novo livro, da leitura ou de qualquer outro assunto que, curricularmente, se aproxime do programa da disciplina que lecciono. Isto para que aquilo que fazemos no ensino universitário ganhe, para os estudantes, um sentido e eles possam aproveitar a reflexão e a experiência quando forem, por seu turno, professores de Língua Portuguesa. Assim, p.e., dado que tenho, entre os meus alunos da licenciatura em Línguas e Literaturas Modernas, alguns da variante Estudos Portugueses e Espanhóis, utilizei, no ano lectivo passado, dois textos da imprensa escrita que poderiam interessar-lhes particularmente ${ }^{2}$.

1. Fonseca, F. I. e Fonseca, J. (1977). Pragmática Linguística e Ensino do Português. Coimbra: Almedina.

2. «Uma história de encantar», in Público, 10 de Novembro de 2003, e «A cortina de tristeza», de Faíza Hayat, in Xis, Público, 22 de Março de 2003. 
Os textos dos media (alguns deles) prestam-se particularmente bem a ser trabalhados do ponto de vista do desenvolvimento da competência leitora, sobretudo no que diz respeito ao treino da capacidade de retirar informação relevante do texto (aquilo a que os Programas oficiais chamam «leitura para informação e estudo»), para, posteriormente, a partilhar, discutir criticamente, relacionar com outros textos, experiências e convicções pessoais ou estados de coisas. O professor terá, obviamente, de traçar objectivos e tarefas de leitura claros e explicitar com objectividade estratégias eficazes.

A partir de textos dos media, é fácil organizar uma sequência em que os alunos retirem informação do texto, a armazenem, a exponham oralmente, a completem com outras informações entretanto recolhidas, leiam (escutem / vejam) outros textos depois.

Talvez um exemplo rápido ilustre o que quero dizer. Podemos levar os alunos a fazer predições a partir de um título. Seja: «O regresso das cegonhas» $»^{3}$. A primeira hipótese que os leitores colocam é a de o texto que tem este título tratar de educação ambiental, da protecção a uma espécie animal ameaçada ${ }^{4}$. Poderse-á, então, encaminhar os alunos para uma pesquisa sobre as cegonhas que envolva os livros escolares e outros professores, CDroms, internet, a versão portuguesa da National Geographic (ou uma estrangeira, se neste projecto se pretender também incluir as disciplinas de língua estrangeira).

Mas voltemos ao texto. Trata-se de fazer, a partir dele, perguntas que apelem ao raciocínio inferencial e não apenas à descodificação de um sentido literal. Podemos começar por descrever a imagem que acompanha o texto e por perguntar aos alunos o que ela lhes sugere. Se o título for contraposto à imagem, os alunos serão levados a modificar a previsão de leitura inicial e perceberão, previsivelmente, que «o regresso das cegonhas» é uma metáfora para se

3. In Público, 4 de Março de 1998.

4. A secção do jornal em que o texto se encontra - Sociedade - não fornece uma pista segura, isto pressupondo que os alunos deverão ser ensinados a relacionar os textos com os lugares dos jornais em que aparecem. 
falar do aumento da natalidade 5 . Deverão, a meu ver, tentar explicar como o funcionamento de tal metáfora é possível e por que razão conseguem fazer a associação que lhe subjaz. Trata-se de ler o texto de forma não preguiçosa. Após a leitura do primeiro parágrafo (talvez até «cada um» $»^{6}$ ), os alunos poderão tentar adivinhar de que se irá falar a seguir, ou seja, fazer antecipações a partir de dados textuais. Deverão, depois, perceber a que perguntas o texto responde ${ }^{7}$. Terão, por hipótese, de explicar o que quer dizer determinada passagem menos clara ou mais metafórica, parafrasear certos segmentos. Em suma, podem resumir cada parágrafo ou parte, descobrir palavras-chave, perguntar, clarificar, predizer, inferir, descodificar implícitos, relacionar com o que sabem ou com a imagem do jornal (ou outras, como a famosa cegonha que traz, no bico, um bebé).

Quando tiverem lido o texto, estarão em condições de levar a cabo novas recolhas de informação, desta vez sobre a evolução da natalidade no nosso país e no mundo ${ }^{8}$. Será uma boa ocasião para interpretarem, verbalmente, gráficos, fazerem exposições orais mais ou menos longas, com ou sem guião previamente preparado?.

5. Esta alteração das previsões não é automática. Os miúdos poderão descrever a imagem oralmente, dizer que ideias lhe associam e talvez só a leitura da legenda lhes permita relacionar o título com a questão demográfica: «Os números indiciam que os portugueses poderão estar a abandonar a opção pelo filho único».

6. «Apesar de só apetecer uma fatia de bolo, comiam-se duas. Tudo porque era mais certo que caso se esperasse uma hora só que fosse, os "queridos maninhos" não deixariam nem uma migalha. O mesmo se passava com as batatas fritas, com os sacos de rebuçados, com as coisas mais deliciosas. Havia que engolir tudo e depressa. Estava-se entre os anos 60 e 70 e naquele tempo usava-se encher de irmãos as casas de cada um». (in Público, 04/04/98).

7. Por exemplo: os $3^{\circ}$ e $4^{\circ}$ parágrafos do texto enumeram possíveis explicações para a diminuição da natalidade: o exôdo para as cidades, com duas consequências (afasta as crianças dos avós e reduz o espaço habitacional), os desafios profissionais, o decréscimo da taxa de mortalidade infantil, a mudança do papel da mulher na sociedade.

8. No mesmo jornal Público, de 21 de Janeiro de 98, ver, por exemplo, o texto «Natalidade volta a subir». Seria interessante estudar e descrever a imagem que o acompanha e tentar prever, a partir dela, qual será o assunto do texto que está a ilustrar. 9. As exposições orais, para o aluno captar o auditório e não se enredar no plano, poderão ser ajudadas por apresentações em powerpoint. Mais do que os passos aliás fáceis a dar, do ponto de vista informático, importa ensinar aos alunos a não transformarem cada diapositivo num texto a ler, monotonamente, de modo expositivo. 
Estarão, portanto, a relacionar a competência de leitura com a competência de produção oral em contexto formal e público. Neste momento, quer a Geografia quer a Matemática (ver o texto «Mais cinco por cento de bebés») deverão entrar em cena.

São várias as vantagens que os textos dos media oferecem, dentro da perspectiva de leitura que vimos defendendo. Permitem o contacto dos alunos com textos de diferentes tipologias, da imprensa escrita, da rádio e da televisão, da internet, variando os suportes, os aspectos gráficos. Vêm, frequentemente, acompanhados de informações dadas por imagens, gráficos, esquemas e outros documentos que não só completam as informações fornecidas no texto principal, como são de leitura relevante, quer dizer, é de toda a conveniência que os alunos também sejam capazes de a elas aceder. São textos geralmente com actualidade, que têm a ver com o que se passa no mundo e com a realidade que cerca os alunos. Normalmente, o registo de língua em que tais textos são produzidos é o corrente, espera-se que em português padrão, de acesso não excessivamente complicado. Acresce que são textos «frescos» na sua novidade diária, muitas vezes capazes de refrescar, com a sua entrada na sala, o modo de abordar conteúdos previstos nos programas das mais variadas disciplinas. E têm, sempre, espaço na aula de Língua Portuguesa, porque a leitura para informação e estudo faz parte das modalidades referidas nos respectivos Programas ${ }^{10}$. Segundo a opinião de Luís Prista (num artigo bastante interessante, embora de certo modo polémico $\left.{ }^{11}\right)$, os textos informativos e expositivos estariam bem calhados para o treino específico da competência leitora, mais do que os habituais textos literários geralmente narrativos omnipresentes nos manuais de Língua Portuguesa. O mesmo se poderá dizer, creio, de textos da

10. Este envolvimento obriga o professor de LP a conhecer os programas das outras disciplinas, o que fazem os colegas dessas disciplinas e de áreas não curriculares, num esforço de construção de projectos comuns que permitam conferir um sentido à leitura ou a outra recolha de informações, porque essa informação vai servir para um qualquer fim que se torna, facilmente, numa forma natural de motivação.

11. Prista, L. (1998). "Textos e preparação do ensino», in A língua mãe e a paixão de aprender. Actas do $2^{\circ}$ Encontro de Professores de Português. Homenagem a Eugénio de Andrade. Porto: Areal Editores. Pp. 36-52. 
rádio ou da televisão, a partir dos quais os alunos melhorem a capacidade de escuta activa e crítica, por exemplo. Estes textos são particularmente úteis para treinar algumas capacidades finas que fazem parte da competência leitora: saber identificar, rapidamente, o tema de um texto, reconhecer indícios textuais relevantes para a compreensão dele, localizar informação, reter sequências temporais de eventos, distinguir factos de opiniões, variar a leitura consoante os objectivos da tarefa, conseguir saltar sequências textuais, recuperando a informação, se necessária, fazer predições, antecipações e verificar se foram bem feitas, etc. (cf. Costa, M.A., 1996).

Os textos explicativos ou informativo-expositivos a ler podem ser, obviamente, os que fazem parte dos manuais escolares das diferentes disciplinas. O professor de Língua Portuguesa deve usar o livro de História para, a partir da leitura de textos nele incluídos, ensinar os alunos a retirarem a informação relevante, por exemplo. Mas talvez seja mais interessante se a História chegar aos alunos também através de uma notícia, uma reportagem, um programa televisivo de divulgação. No dia 6 de Junho de 2003, a última página do diário Público trazia uma notícia sobre conclusões tiradas a partir da análise de esqueletos de gladiadores descobertos, em escavações recentes, no Coliseu de Roma. Dado que os alunos de $7^{\circ}$ ano de escolaridade estavam, nessa mesma ocasião, a estudar a civilização romana, a ligação entre as disciplinas de Língua Portuguesa e de História poder-se-ia fazer pela leitura para recolha de informação do referido texto, com eventual resumo escrito (ou oral) do mesmo, a apresentar, também, na aula de História.

Há, no entanto, duas ressalvas que as convicções anteriormente expostas exigem.

A primeira diz respeito ao tratamento dos textos enquanto material linguístico e discursivo e não só enquanto fonte de recolha de informações. Quer dizer: não penso que os textos sirvam apenas para serem lidos, para com eles treinarmos a competência de leitura, strictu sensu. Também são úteis (e daí não concordar eu totalmente com o artigo referido de Luís Prista) para trabalhar a língua, a sua estrutura e o seu funcionamento. 
Devem ser, igualmente, estudados enquanto textos, com as suas regularidades e especificidades próprias que os alunos têm vantagens em conhecer, até para poderem produzir, quando for caso disso, os seus próprios textos, orais ou escritos, com regras explicitáveis e ensináveis, de acordo com o que nos diz a Linguística textual e discursiva.

Por outro lado, alguns textos dos media merecem ser lidos, pela sua qualidade intrínseca, de forma orientada e metódica, porque são excelentes no modo como trabalham a língua e os seus recursos. Refiro-me, neste ponto, a três tipos de textos dos media. Em primeiro lugar, a pequenos contos ou crónicas de escritores connhecidos que publicam nos jornais. No caso do Público, estou a pensar em lindíssimos textos de escritores tão consagrados quanto Mia Couto, José Eduardo Agualusa ou Cardoso Pires. Mas Lobo Antunes escreve na revista Visão, por exemplo. Em segundo lugar, será desperdício não aproveitar as crónicas, algumas muito interessantes e bem escritas, sobre escritores, obras literárias do cânone e mesmo questões mais ou menos leves do quotidiano. São textos que estilhaçam, por vezes, as distinções académicas mais ou menos rígidas entre o literário e o não-literário e, até por isso, por permitirem desafiar algumas certezas demasiado arreigadas, merecem atenção. Lembro, de passagem, "O sino da minha aldeia», uma crónica de Eduardo Prado Coelho ${ }^{12}$, que pode ajudar-nos a ler o poema de Fernando Pessoa ortónimo com o mesmo nome, ou de «Mergulho no dia como em mar...», de Joaquim Fidalgo, crónica que fala, de um modo belíssimo, da poesia de Sophia de Mello Breyner. Por último, há textos de imprensa como reportagens, notícias, crónicas de televisão, peças de uma polémica, editoriais, etc., que são verdadeiras preciosidades ${ }^{13}$.

12. Coelho, E.P., «O sino da minha aldeia», in Público de 14 de Novembro de 2001. 13. Por isso mesmo, Joaquim Fonseca tem estudado, com especial rigor e eficácia, alguns textos de opinião e editoriais, nomedamante do Público. Porque são textos argumentativamente bem construídos. Ver, por exemplo, Fonseca, J. (1994). Pragmática e Linguística. Introdução, Teoria e Descrição do Português. Porto: Porto Editora, e Fonseca, J. (2001). Lingua e discurso. Porto: Porto Editora. 
A segunda ressalva diz respeito à ligação entre os media e a leitura de textos literários, ou entre os media e a leitura puramente recreativa. Embora pense que a forma de acesso mais sólida para a cultura se faz pela leitura literária também sei que nem todos somos obrigados a ler os mesmos textos. Não descarto, portanto, a possibilidade de haver alunos que cheguem à leitura por outras vias: lendo jornais desportivos (ou apenas as secções desportivas dos jornais), lendo textos de divulgação científica, musical ou outros a seu gosto.

O importante é que o professor abra aos alunos o máximo de portas para a leitura, como forma de eles acederem a outros mundos e a outras palavras mais ricas para dizer esses mundos e $\mathrm{o}$ nosso. Neste desígnio (como noutros, aliás), o contacto variado com textos dos media pode constituir-se numa ajuda de grande utilidade. Muito material recolhido nos media pode servir de catalizador da vontade de ler romances, a obra poética de um autor de quem se leu um poema no jornal, a propósito de uma efeméride, por exemplo. A celebração recente dos 80 anos de António Ramos Rosa deu lugar a textos/programas de televisão ou rádio que podem ser portas de entrada suaves nos poemas do escritor ${ }^{14}$.

A colecção infanto-juvenil publicada pelo jornal Público vem acompanhada, nas páginas do jornal, por uma apresentação muito atraente das diferentes narrativas. Esses textos podem ser usados pelos professores de Língua Portuguesa como modo de dar a conhecer os livros e de criar a vontade de os ler.

O mesmo se passa com algumas entrevistas que os escritores concedem a propósito do lançamento dos seus livros. Recordo, apenas a título de exemplo, o tratamento que podemos dar, na aula de Português, à entrevista de Miguel Sousa Tavares ao Público ${ }^{15}$. Para além do trabalho sobre um tipo de texto concreto (a entrevista), a leitura dele talvez aguce o desejo dos leitores para a do romance Equador.

14. Ver, por exemplo, o Suplemento «Mil Folhas» do Público de 23 de Outubro de 2004.

15. Ver Público, suplemento «Mil Folhas», 13 de Dezembro de 2003. 
Repito o que escreveu, numa crónica na revista Visão (de 13 de Fevereiro de 2003), António Mega Ferreira: «não se pode forçar a ser leitor quem não tem vontade de ler». Mas pode-se, com mais ou menos engenho, provocar a curiosidade do aluno em relação à leitura. Pessoalmente, acredito que a responsabilidade do professor de Língua Portuguesa é enorme a este respeito. Continuo a pensar que a melhor forma de aceder à leitura por prazer é através da literatura, nomeadamente da narrativa de ficção e do efeito que ela produz no leitor, de criação de mundos alternativos e experienciação de vivências alheias, de possibilidade de fuga ao aqui e agora de quem lê (cf. Fonseca, F.I. 1994), de ultrapassar a mera capacidade de comunicação. Escreve Fernanda Irene Fonseca:

A aquisição de uma capacidade de autonomização da linguagem em relação aos suportes e urgências imediatos de uma situação concreta de interacção é também coadjuvante da aquisição de uma capacidade de estruturação do pensamento e do raciocínio de tipo discursivo, indispensáveis à assimilação de conhecimentos e à construção do conhecimento. (Fonseca, F.I., 1994: 155)

Os media, na sua variedade e novidade diárias, permitem que o professor e também os alunos escolham, decidam, programem o que vão ler, ouvir, analisar, sem terem de obedecer à tirania de um manual que, ano após ano, por vezes, impõe os mesmos textos e as mesmas leituras, com essa prática condicionando, como Maria de Lurdes Dionísio ${ }^{16}$ mostrou, a própria concepção que os alunos têm do que seja «ler». Quando bem utilizados, na aula de Língua Materna, familiarizam o aluno com a modalidade escrita, facilitam o seu contacto com a língua, potenciam a sua aproximação à leitura e talvez à escrita, estimulam o espírito crítico e a sensibilidade estética.

16. Dionísio, M.L. (2002). A construção escolar de comunidades de leitores. Leituras dos manuais escolares. Coimbra: Almedina. 


\section{REFERÊNCIAS BIBLIOGRÁFICAS}

Costa, M.A. (1996). «Se a língua materna não se pode ensinar, que professores temos de formar?». In Delgado-Martins, M. R. et alii (org.). Formar professores de português, hoje. Lisboa: Edições Colibri, pp. 75-84.

Dionísio, M.L. (2002). A construção escolar de comunidades de leitores. Leituras dos manuais escolares. Coimbra: Almedina.

FonseCA, F.I., (1994). Gramática e Pragmática: Estudos de Linguística Geral e de Linguística Aplicada ao Ensino do Português. Porto: Porto Editora.

FonseCa, J. (1994). Pragmática e Linguística. Introdução, Teoria e Descrição do Português. Porto: Porto Editora.

Fonseca, J. (2001). Lingua e discurso. Porto: Porto Editora.

PRISTA, L. (1998). «Textos e preparação do ensino». In A língua mãe e a paixão de aprender. Actas do $2^{\circ}$ Encontro de Professores de Português. Homenagem a Eugénio de Andrade. Porto: Areal Editores, pp. 36-52. 
